UDK 61.615.32.322

\title{
IDENTIFICATION OF CALYSTEGINES IN PLANTS OF FAMILY ERICACEAE WITH GAS CHROMATOGRAPHY - MASS SPECTROMETRY METHOD
}

\author{
() N. Asano ${ }^{1}$, O.G. Strusovskaya ${ }^{2}$, D.S. Kosyakov" ${ }^{3 *}$ S.A. Pokryshkin ${ }^{3}$, M.V. Gavrilin ${ }^{4}$, J.V. Mudretsova ${ }^{4}$ \\ ${ }^{1}$ BioApply Co., Ltd., Kanazawa (Japan) \\ ${ }^{2}$ The Northern State Medical University, Arkhangelsk (Russia) \\ ${ }^{3}$ Northern (Arctic) Federal University named after M. V. Lomonosov, Northern Dvina \\ Emb., 17, Arkhangelsk, 163002 (Russia), e-mail: kosyakov@mail.ru \\ ${ }^{4}$ Pyatigorsk branch of Volgograd State Medical University, Pyatigorsk (Russia)
}

In Russia, folk-medicinal plants of the family Ericaceae are often used for the treatment of diseases associated with hyperglycemic states. It is known that calystegines, a group of compounds of nortropane alkaloids, have the unique ability of competitive inhibition of glucosidases activity. The objective of this study was to identify calystegines in the chemical composition of plants growing on the islands of Solovetsky Archipelago and belonging to the family Ericaceae: Vaccinium vitis-idaea (lingonberry or cowberry); Vaccinium myrtillus (bilberry); Oxycoccus palustris (cranberry); Empetrum hermaphroditum (crowberry, a common name also used for corema); Arctostaphylos uva-ursi (bearberry) and Ledum palustre (marsh tea, wild rosemary).

Preliminary data for the detection of the chemical composition of the studied plants were obtained by capillary zone electrophoresis and further research was carried out by gas chromatography coupled to tandem mass spectrometry.

Thus, the presence of calystegines in plant samples of family Ericaceae has been confirmed in the course of the research. It was found that calystegine B2 presents in all samples tested and is dominant. Calystegine B1 was found in cowberry and cranberry. The presence of calystegine B3 was convincingly confirmed only in lingonberry.

The presence of calystegines in the chemical composition of studied plants is one of the reasons of explaining their use in folk medicine for treating of hyperglycemic states.

Keywords: plants, Ericaceae, calystegines, CE, GC-MS/MS.

\section{Introduction}

In Russia, folk-medicinal plants of the family Ericaceae are often used for the treatment of diseases associated with hyperglycemic states. The family Ericaceae includes more than 3000 species belonging to 100 genera. In flora of Russia, there are 54 species of this family, and only four species are officinal herbs, Arctostaphylos uva-ursi L. (L.) Spreng., Vaccinium vitis-idaea L., Vaccinium myrtillus L. and Ledum palustre L. [1].

It is known that calystegines, a group of compounds of nortropane alkaloids, have the unique ability of competitive inhibition of glucosidases activity [2]. The objective of this study was to identify calystegines in the chemical com-

Asano Naoki - Chief Executive Officer, PhD, e-mail: Asanaok@gmail.com

Strusovskaia Ol'ga Gennad'evna - Associate Professor, Department of Pharmacology, the candidate of pharmaceutical sciences, e-mail: strol3@yandex.ru Kosiakov Dmitrii Sergeevich - Director of the Center for collective use scientific association «Arctic», Ph.D. Associate Professor, e-mail: kosyakov@mail.ru

Pokryshkin Sergei Aleksandrovich - Junior Researcher, e-mail: serge.physchem@yandex.ru

Gavrilin Mikhail Vital'evich - Doctor of Pharmacy, professor, e-mail: farmnauka@mail.ru

Mudretsova Iuliia Viktorovna - Lecturer, Department of Pharmaceutical and Toxicological Chemistry, Candidate of Pharmaceutical Sciences, e-mail: farmnauka@mail.ru position of plants growing on the islands of Solovetsky Archipelago and belonging to the family Ericaceae: Vaccinium vitis-idaea (lingonberry or cowberry); Vaccinium myrtillus (bilberry); Oxycoccus palustris (Cranberry); Empetrum hermaphroditum (crowberry, a common name also used for Corema); Arctostaphylos uva-ursi (bearberry) and Ledum palustre (marsh tea, wild rosemary).

Preliminary data for the detection of the chemical composition of the studied plants were obtained by capillary zone electrophoresis (CE) [3] and further research was carried out by gas chromatography coupled to tandem mass spectrometry (GC-MS/MS).

\footnotetext{
* Corresponding author.
} 


\section{Experimental}

Wild herbal species belonging to the family Ericaceae and growing on the islands of Solovetsky Archipelago were collected in July and August 2011. Plant materials were identified at the Department of Pharmacy and Pharmacology of the Northern State Medical University, Arkhangelsk, Russia. In the present study, dried leaves of investigated plants were used. Standard samples of calystegines (A3, B1, B2 and B3) were kindly donated by Dr. N. Asano (BioApply Co., Ltd., Kanazawa, Japan).

All other chemicals and solvents were of analytical grade (Sigma Aldrich). Ultrapure water, obtained by a Millipore Milli-Q system (Bedford, MA, USA), was used for standard and sample preparation. Electrolyte solutions were filtered through a 0,45 mm nylon membrane (Supelco, Belle fonte, PA, USA) before use.

Capillary electrophoresis data were obtained using a CE system «Capel 105» (Lumex, Russia) equipped with variable wavelength UV-detector (wavelength range 190-380 nm) and autosampler. The capillary length was $75 \mathrm{~cm}$ (effective length $65 \mathrm{~cm}$ ), internal diameter $50 \mu \mathrm{m}$, detection wavelength $191 \mathrm{~nm}$, temperature $50{ }^{\circ} \mathrm{C}$; voltage of $25 \mathrm{kV}$. The injection by pressure was used $(50 \mathrm{mbar} \times 5 \mathrm{sec})$.

Before use, the capillary washed with $0,5 \mathrm{M}$ solution of hydrochloric acid during $20 \mathrm{~min}$, then by water for $10 \mathrm{~min}$, after that by $0,5 \mathrm{M}$ solution of sodium hydroxide for $20 \mathrm{~min}$. Then the capillary was washed again with water for $10 \mathrm{~min}$. During analysis, the capillary was successively washed with $0,5 \mathrm{M}$ solution of sodium hydroxide for $2 \mathrm{~min}$, followed by water for $2 \mathrm{~min}$, and then equilibrated with the running buffer for $3 \mathrm{~min}$.

The carrier buffer was prepared by dissolving sodium tetraborate in water to give a concentration of $80 \mathrm{mM}$ and, if necessary, adding sodium hydroxide solutions to give a $\mathrm{pH}$ exactly 9,2 [3].

GC-MS data were collected using Agilent 7000 QQQ Triple Quadrupole system (Agilent, USA), equipped with capillary column HP-5MS, 0,32 mm i.d. x $30 \mathrm{~m}, 0,25 \mu \mathrm{m}$ stationary phase. The following parameters of analysis were used. Split ratio $1: 20$. Injector temperature $170^{\circ} \mathrm{C}$. Carrier gas - helium. Control of gas flow - constant speed. The flow rate through the column $-1 \mathrm{ml} / \mathrm{min}(27,9 \mathrm{~cm} / \mathrm{sec})$. Temperature program of thermostat: $150{ }^{\circ} \mathrm{C}$ for $3 \mathrm{~min}$, rise at $10{ }^{\circ} \mathrm{C} / \mathrm{min}$ up to $240{ }^{\circ} \mathrm{C}$. MS interface temperature $230{ }^{\circ} \mathrm{C}$. Ion source temperature $230{ }^{\circ} \mathrm{C}$. The ionization energy $-70 \mathrm{eV}$. Detector voltage $-1,8 \mathrm{kV}$. CID gas: nitrogen, $1 \mathrm{ml} / \mathrm{min}$. Quench flow: $\mathrm{He}, 2 \mathrm{ml} / \mathrm{min}$.

The compounds have been identified by combined gas-chromatographic and mass spectrometric analysis (GC-MS/MS) comparing retention times and fragmentation patterns with standard samples.

The standard solutions of calystegines $(1 \mathrm{mg} / \mathrm{ml})$ for $\mathrm{CE}$ analysis were prepared in $50 \%$ aqueous ethanol. All prepared solutions were filtered and centrifuged at $7000 \mathrm{rpm}$ for 5 minutes. To prepare the model mixture including all standard solutions, standard samples were mixed in the ratio $1: 1: 1: 1$.

All dried leaf samples of investigated plants, $10 \mathrm{~g}$ of each were homogenized in $100 \mathrm{ml} 50 \%$ aqueous ethanol and allowed to stand for 24 hours at room temperature.

For $\mathrm{CE}$ analysis the extracts were filtered through a $0,25 \mu \mathrm{m}$ filter before injection.

For GC-MS analysis, ethanol-water extracts in each case was filtered. The filtrates were evaporated under vacuum to give brown syrups in amount of about $1 \mathrm{ml}$. These syrups were loaded onto glass columns packed with the $10 \mathrm{~g}$ of Amberlite IR-120B ( $\mathrm{H}^{+}$form). Sugars and phenolic compounds were washed from the column with distilled water to give a neutral $\mathrm{pH}$ value. The calystegines were eluted with $2 \mathrm{M}$ ammonium hydroxide solution. Ammonium was removed from the resulting solutions by evaporation under vacuum at $40{ }^{\circ} \mathrm{C}$ to obtain amount of about $1 \mathrm{ml}$ and lyophilized [5].

For derivatization, the dry plant extracts were dissolved in $500 \mu \mathrm{l}$ of pyridine and allowed to stand for $10 \mathrm{~min}$. After that supernatant $(40 \mu \mathrm{l})$ placed into an Eppendorf centrifuge tube, added $70 \mu \mathrm{l}$ silylating agents (HMDS + TMCS $3: 1$ ). The tubes were tightly capped and the contents were mixed using Vortex. Then tubes kept at $55{ }^{\circ} \mathrm{C}$ for $15 \mathrm{~min}$. Then, the tubes were cooled for $30 \mathrm{~min}$ to room temperature and centrifuged at $14800 \mathrm{rpm}$ during $5 \mathrm{~min}$. Supernatant was taken into the GC vial and used for analysis.

\section{Results and discussion}

Since complexation of borate ions with vicinal or alternate hydroxyl groups under alkaline conditions gives compounds which can be detected by UV at low wavelength [3], we used capillary electrophoresis method for identification of calystegines in the samples of extracts of E. hermaphroditum and V. vitis-idaea.

For this aim, the electropherograms of the model mixture of the standards of calystegines were obtained. Typical electropherogram of calystegines model mixture is presented in Fig.1. 
The migration time was $425 ; 447.7 ; 467.5$ and $624.9 \mathrm{sec}$, peaks efficiencies were $243587 ; 146029 ; 19462$; 167034 TP for the standard samples of the calystegines B1; A3; B2 and B3, respectively.

The calystegines in plant extracts were identified by the values of migration time.

The electropherograms of calystegines in plant extracts are presented in Fig. 2.

In the course of preliminary studies, the presence of calystegines A3 and B2 in the chemical composition of E. hermaphroditum, and calystegines A3 and B3 in chemical composition V. vitis-idaea has been shown.

The confirmation of the presence of identified calystegines of B-group and determination them in plant extracts were done using the method of tandem mass spectrometry in order to provide structural information for the identification.

Analysis of the model mixture of trimethylsilyl (TMS)-derivatized standard samples of calystegines by capillary GC demonstrated that retention time for each of them were 10,66, 10,78 and 11,72 min for TMS of calystegines B3, B1 and B2, respectively, in chosen conditions (Fig. 3).

GC analysis of the investigated TMS derivatives of lyophilized plant extracts in scan mass range detected peaks, approximately corresponding to the retention time of authentic samples of calystegines: calystegine B1 (in extracts from E. hermaphroditum and O. palustris leafs); calystegine B2 (in all plant extracts) and calystegine B3 (only in extract from $V$. vitis-idaea leafs).

Fig. 1. Typical

electropherogram of the model mixture of the standards of calystegines
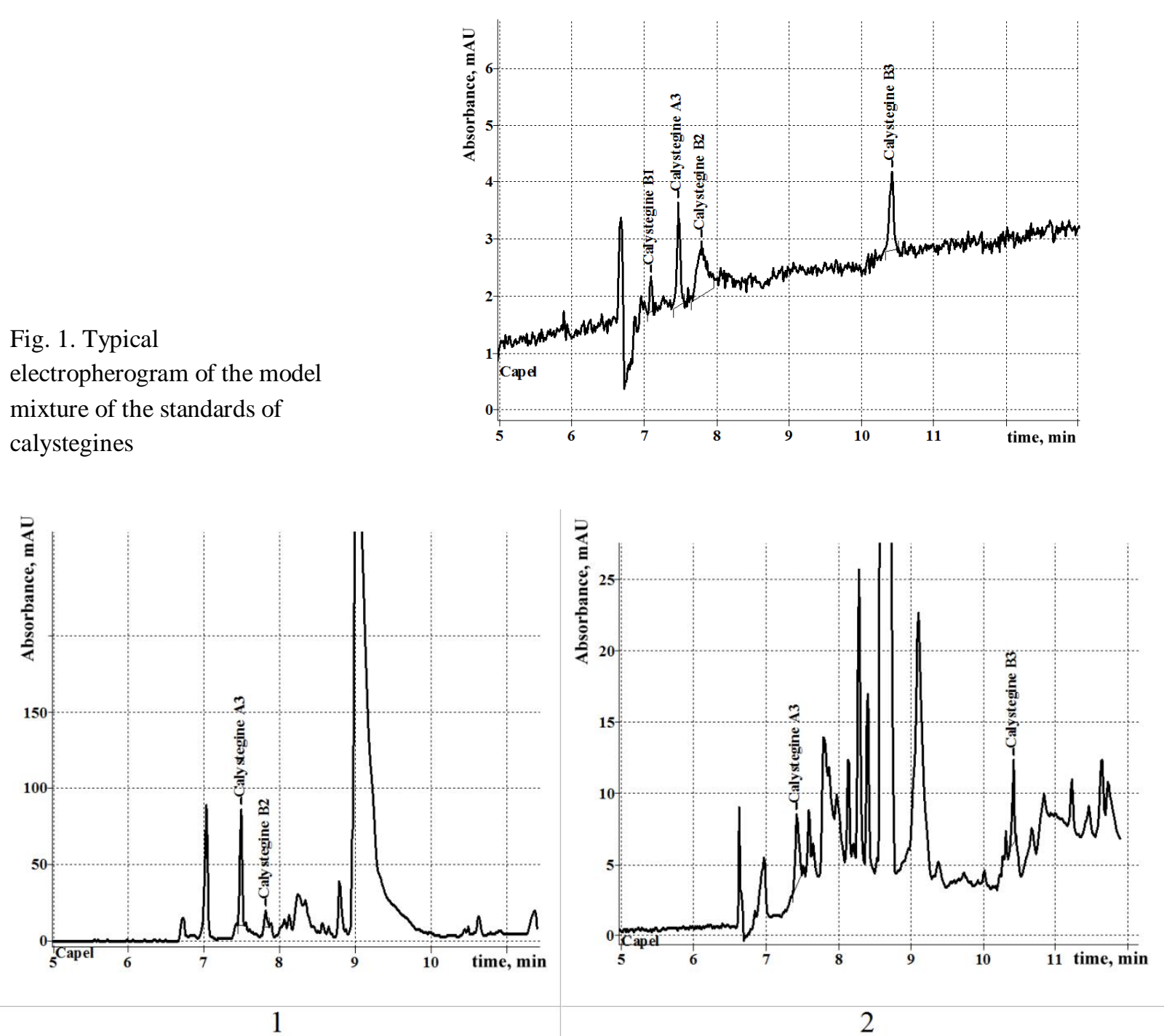

Fig. 2. The electropherogramms of the plant extracts: $1-$ E. hermaphroditum; $2-V$. vitis-idaea 


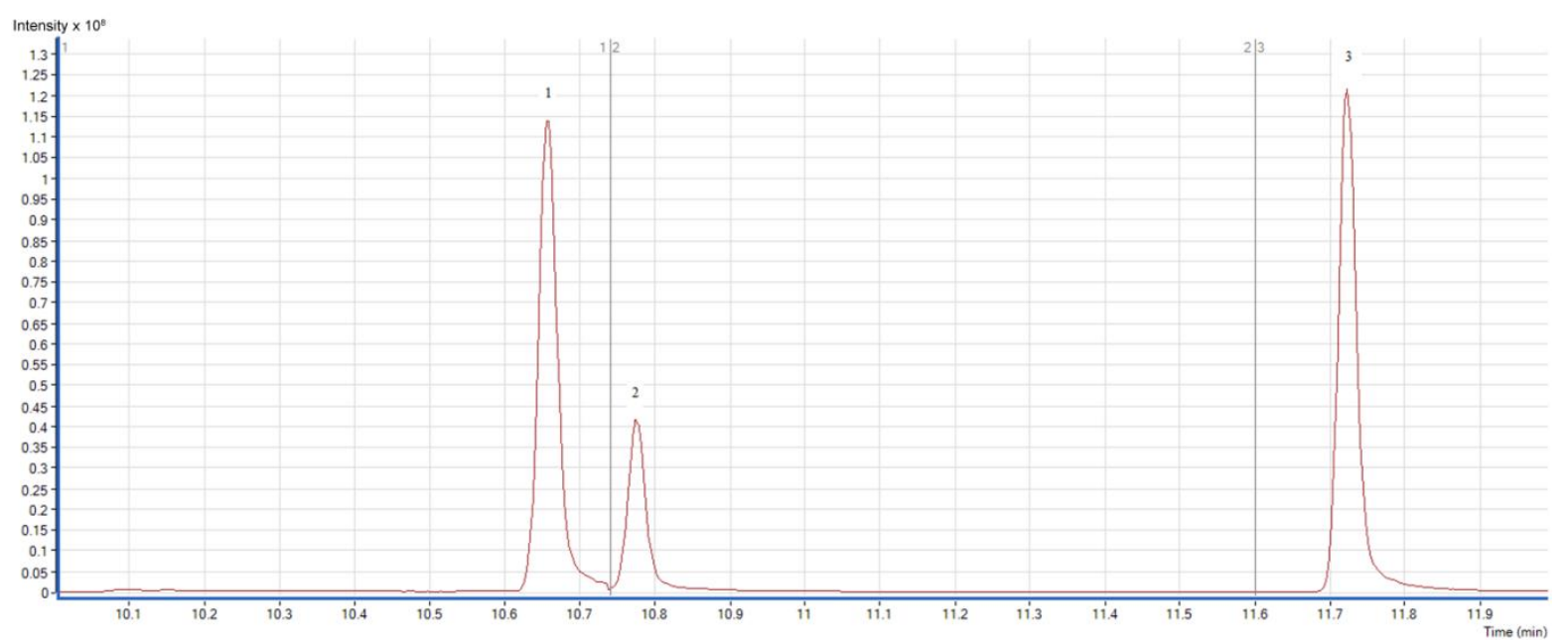

Fig. 3. The chromatogram of the model mixture of TMSi-derivatized standard samples of calystegines: 1 - calystegine B3; 2 - calystegine B1; 3 - calystegine B2

The mass spectra corresponding to these peaks were identified as TMS derivatives of sugars, furanose and pyranose types by base of the Library NIST-08. However, there are a number of peaks in mass spectra, uncharacteristic for TMS derivatives of sugars but typical for TMS derivatives of calystegines, so the analysis selectivity was insufficient because of very complex composition of plant extracts.

We used multiple reaction monitoring (MRM) technique to enhance the selectivity of the analysis for positive identification of calystegines in the tests. By the injection of model mixture of TMS derivatives of calystegine standards the characteristic precursor ions were identified and specific MRM-transitions were selected, the collision energy and the flow of CID gas in the collision cell were optimized to ensure the best signal/noise ratio (SNR) for the target compounds. The obtained conditions are given in Table.

The $\mathrm{MS}^{2}$ spectra of calystegine B2 prevail in all extracts and its authentic sample was recorded to confirm the presence of calystegines in plant extracts. Recording was carried out in the scan mode product ion monitoring (parent ion 217,5, collision energy 15eV) (Fig. 4).

Presence of calystegines B1 and B3 in the plant extracts was identified by retention times of the peaks in the chromatograms, as well as by compliance ratio of the peak areas of the two MRM-transitions defined for standard samples.

The optimal conditions of MRM-analysis of calystegines

\begin{tabular}{c|c|c|c|c|c}
\hline Calystegines & $\begin{array}{c}\text { Retention } \\
\text { time, min }\end{array}$ & $\begin{array}{c}\text { (Gain) amplifica- } \\
\text { tion of the signal }\end{array}$ & MRM -transitions & $\begin{array}{c}\text { Dwell time, } \\
\text { msec }\end{array}$ & $\begin{array}{c}\text { Collisions } \\
\text { energy, eV }\end{array}$ \\
\hline B1 & 10,78 & 30 & $244,5 \rightarrow 129,1$ & 100 & 10 \\
& & & $244,5 \rightarrow 75,0$ & 100 & 15 \\
B2 & 11,72 & 10 & $217,5 \rightarrow 143,0$ & 100 & 10 \\
& & & $217,5 \rightarrow 73,0$ & 100 & 20 \\
B3 & 10,66 & 10 & $217,5 \rightarrow 143,0$ & 100 & 10 \\
& & & $217,5 \rightarrow 73,0$ & 100 & 20 \\
\hline
\end{tabular}

CID gas: nitrogen, $1 \mathrm{ml} / \mathrm{min}$. Quench flow: $\mathrm{He}, 2 \mathrm{ml} / \mathrm{min}$ 


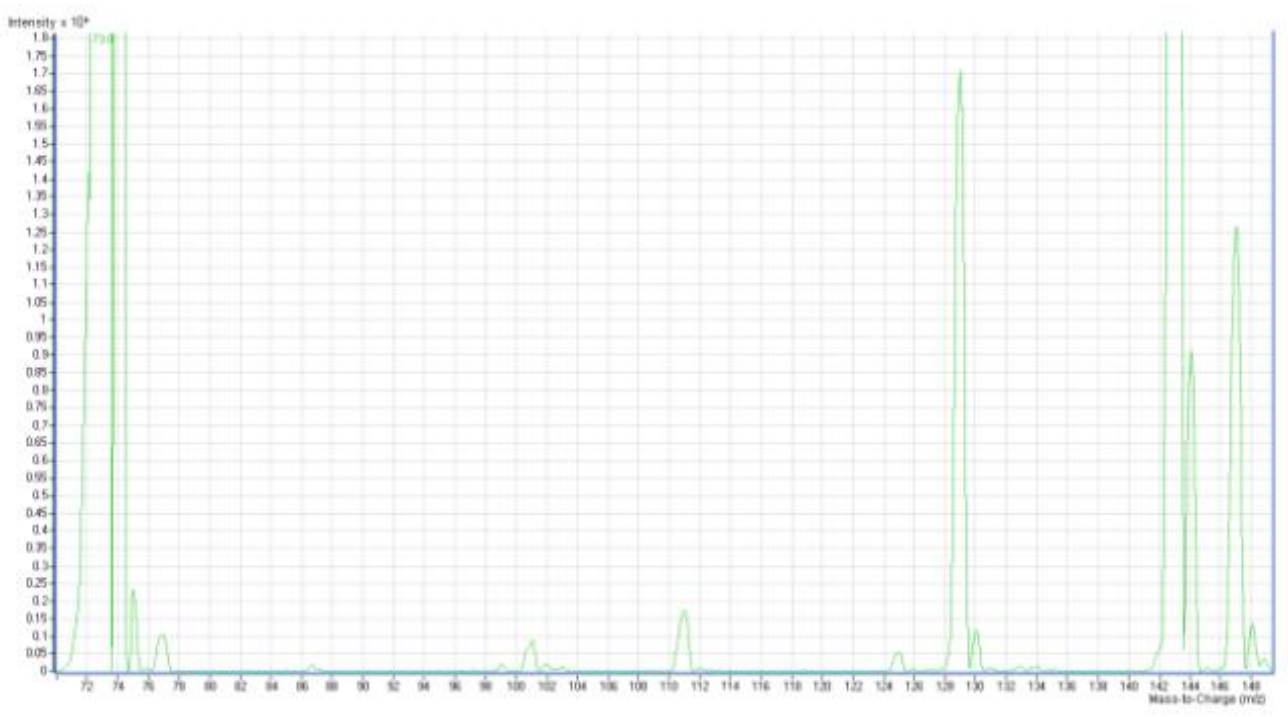

1

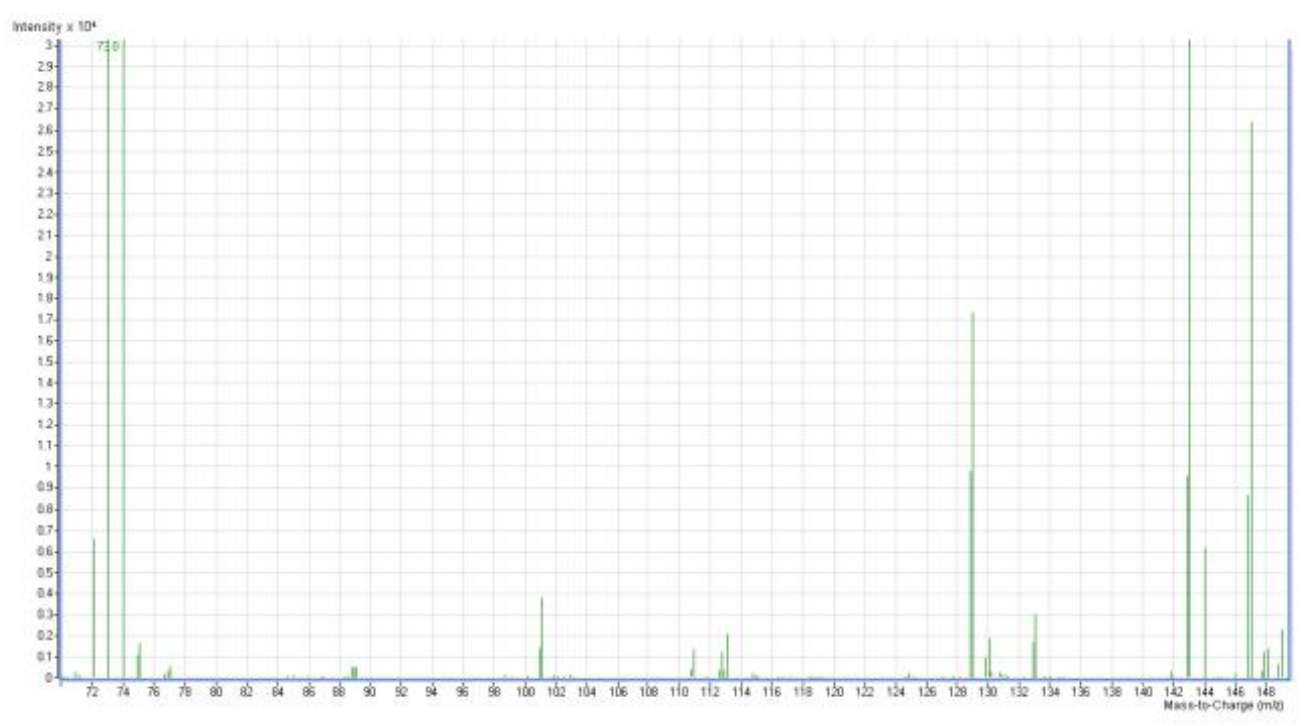

2

Fig. 4. The spectrum of ion-decay products of calystegine B2: 1 - The spectrum of ion-decay products of calystegine B2; 2 - The typical spectrum of ion-decay products of the compound with retention time 11,72 min in chromatogram of plant extracts

\section{Conclusion}

The presence of calystegines in plant samples of family Ericaceae has been confirmed in the course of the research. It was found that calystegine B2 presents in all samples tested and is dominant. Calystegine B1 was found in lingonberry and cranberry. The presence of calystegine B3 was convincingly confirmed only in lingonberry.

The presence of calystegines in the chemical composition of studied plants is one of the reasons explaining their use in folk medicine for treating of hyperglycemic states.

\section{Acknowledgements}

Some parts of science work was done using the instrumentation of the Joint Use Center of Research Equipment «Arctica» of Northern (Arctic) Federal University named after M.V. Lomonosov under financial support of Ministry of Science and Education of Russian Federation. 


\section{References}

1. State Pharmacopoeia USSR. Eleventh ed., Vol. 2. Common methods of analysis. Medicinal plant material. Moscow, 1990. 400 p. (in Russ.).

2. Asano N., Kato A., Matsui K., Watson A.A., Nash R.J., Molyneux R.J., Hackett L., Topping J., Winchester B. Glycobiology, 1997, vol. 7, no. 8, pp. 1085-1088.

3. Daali Y., Bekkouche K., Cherkaoui S., Christen P., Veuthey J-L. J. of Chromatogr. A, 2000, vol. 903, pp. $237-244$.

4. Keiner H.R. Calystegine in Solanum tuberosum L. - Klonierung, Expression und Charakterisierung der Tropinonreduktasen I und II, putativer Enzyme des Tropanalkaloidstoffwechsels : Dissertation zur Erlangung des akademischen Grades doctor rerum naturalium (Dr. rer. nat.) Halle/Saale, den 14.12.2001.

Received August 5, 2013

Revised October 30, 2013 